\title{
Noninfectious uveitis in the Asia-Pacific region
}

\author{
Yung-Ray Hsu $\mathbb{1}^{1,2}$ • Jerry Chien-Chieh Huang ${ }^{3} \cdot$ Yong Tao ${ }^{4} \cdot$ Toshikatsu Kaburaki $^{5}$. Christopher Seungkyu Lee $\mathbb{1}^{6}$. \\ Tai-Chi Lin ${ }^{7,8} \cdot$ Chih-Chien Hsu $\mathbb{1}^{7,8} \cdot$ Shih-Hwa Chiou ${ }^{8,9} \cdot$ De-Kuang Hwang $\mathbb{D}^{8,10}$
}

Received: 30 June 2018 / Revised: 19 August 2018 / Accepted: 23 August 2018 / Published online: 15 October 2018

(c) The Royal College of Ophthalmologists 2018

\begin{abstract}
Uveitis is a sight-threatening disease. Up to $35 \%$ of patients may have impaired vision. Inflammation of the uvea tissue has more than 60 etiologies. Previous reports have shown that $20-40 \%$ of uveitis cases were noninfectious. Some of them may be associated with systemic rheumatological and autoimmune diseases but some may affect the eyes only. The epidemiology and clinical situations of some specific uveitis entities vary worldwide because they are influenced by genetic, ethnic, environmental, and socioeconomic factors. The Asia-Pacific region comprises more than 30 countries. Epidemiology and patterns of uveitis vary greatly in this region. However, some uveitis entities, such as Behcet's disease, sarcoidosis, and Vogt-Koyanagi-Harada disease, are more common in this region. Many studies on the epidemiology, risk factors, and immune pathogenesis of this disease have been conducted. In this article, we review the epidemiology of noninfectious uveitis and special situations of these three uveitis entities in the Asia-Pacific region.
\end{abstract}

\section{Introduction}

Uveitis is a group of disease entities with more than 60 etiologies. These sight-threatening diseases are defined as intraocular inflammation involving the iris, ciliary body, and choroid, and represent one of the leading causes of visual impairment among the working-age population, contributing to 5-20\% of legal blindness in developed countries. Previous reports have shown that up to $35 \%$ of

These authors contributed equally: Dr. Hsu and Dr. Huang

These authors contributed equally: Dr. Hwang and Dr. Chiou

Shih-Hwa Chiou

shchiou@vghtpe.gov.tw

$\triangle$ De-Kuang Hwang m95gbk@gmail.com

1 Department of Ophthalmology, Far Eastern Memorial Hospital, New Taipei City, Taiwan

2 Department of Ophthalmology, National Taiwan University, Taipei, Taiwan

3 Department of Ophthalmology, Keelung Chang Gung Memorial hospital, Keelung, Taiwan

4 Department of Ophthalmology, Beijing Chaoyang Hospital, Capital Medical University, Beijing, China patients with uveitis experience transient or permanent visual impairment in one or both eyes [1]. These visual disturbances are followed by mainly direct ischemic and inflammatory damage of ocular tissue or serious ocular complications.

Etiologies of uveitis can be classified into four categories. Studies have revealed that $30-60 \%$ of uveitis cases are idiopathic. Localized or systemic infections of virus, bacteria, parasite, or tuberculosis may lead to uveitis. Noninfectious uveitis can be related to systemic rheumatological and autoimmune diseases-such as ankylosing spondylitis, Behcet's disease, sarcoidosis, Vogt-Koyanagi-Harada (VKH) disease, juvenile rheumatoid arthritis, and multiple sclerosis_or can be ocular only

5 Department of Ophthalmology, The University of Tokyo Graduate School of Medicine, Tokyo, Japan

6 Department of Ophthalmology, Severance Hospital, Institute of Vision Research, Yonsei University College of Medicine, Seoul, Korea

7 Institute of Clinical Medicine, National Yang-Ming University, Taipei, Taiwan

8 Department of Ophthalmology, Taipei Veterans General Hospital, Taipei, Taiwan

9 Department of Medical Research \& Education, Taipei Veterans General Hospital, Taipei, Taiwan

10 School of Medicine, National Yang-Ming University School of Medicine, Taipei, Taiwan 
Table 1 Estimated incidence and prevalence of uveitis in Asia-Pacific countries

\begin{tabular}{llllllll}
\hline Country & Year & Sample size & Age group & Incidence $(1 / 10,000)$ & Prevalence $(1 / 10,000)$ & Sex Male: Female & Methodology \\
\hline Australia [13] & 2012 & 1881 & $\geq 20$ years & N/A & 80.0 \& & N/A* & Multi-clinic based \\
China [10] & 2002 & 10,500 & All age & N/A & 15.2 & $1.19: 1$ & Community-based \\
India [12] & 2011 & 5150 & $\geq 40$ years & N/A & 31.7 & $7.76: 1$ & Community-based \\
India [11] & 2000 & 10,000 & $\geq 30$ years & N/A & 73.0 & $1.04: 1$ & N/A \\
Japan [9] & 1996 & $1,800,000$ & All age & N/A & 17.3 & $1.18: 1$ & Questionnaires \\
South Korea [15] & 2018 & $1,000,000$ & All age & 10.6 & 19.4 & $1.23: 1$ & Registry database \\
Taiwan [14] & 2012 & $1,000,000$ & All age & 11.1 & Registry database \\
\hline
\end{tabular}

$\&$ : Prevalence of previous anterior uveitis was $0.21 \%$, and the prevalence of previous posterior uveitis was $0.59 \%$

*: N/A: Data not available

—with etiologies such as multifocal choroiditis, multiple evanescent white dot syndrome, birdshot retinochoroidopathy, serpiginous choroiditis, or Fuchs heterochromic iridocyclitis.

The medications and treatment strategies for uveitis for cases with noninfectious etiologies or from infectious pathogens differ. Therapy for noninfectious uveitis should focus on reducing the severity of inflammation, decreasing the frequency of recurrence, and preventing ocular or systemic side effects. Currently, oral corticosteroids and conventional synthetic immunomodulatory therapy agents, including cyclosporine, tacrolimus, methotrexate, azathioprine, mycophenolate, leflunomide, chlorambucil, and cyclophosphamide, are the mainstays of treatment. Anti-tumor necrosis factor alpha (anti-TNF- $\alpha$ ), interferon, anti-interleukin-6, and other biologic agents have also demonstrated their efficacy in controlling noninfectious uveitis [2]. Recently, an anti-TNF- $\alpha$ antibody, adalimumab, was approved for treating noninfectious nonanterior uveitis in many countries [3, 4].

Generally, infectious uveitis is more common in developing countries, and noninfectious uveitis is more common in developed countries. However, genetic and cultural factors are also associated with some specific uveitis entities. For example, toxoplasmosis infection-induced uveitis represents $10 \%$ of uveitis cases in the United States but constitutes less than $0.1 \%$ of uveitis cases in China [5]. Nevertheless, the incidence of Behcet's disease and VKH disease are much higher in Asian populations than those in Western countries [6-8]. Although countries in the Asia-Pacific region vary greatly in economic status, they share similarities in culture, race, and environments. In this article, we review the epidemiology and recent studies of specific uveitis entities in this region.

\section{Epidemiology and distribution of etiologies}

Incidence and prevalence of uveitis in the Asia-Pacific region have seldom been reported (Table 1). Nakao and
Ohba sent questionnaires to all ophthalmic clinics in Kagoshima prefecture of Japan and estimated that the prevalence of endogenous uveitis in 1996 was 4/10,000 [9]. In 2002, Hu et al. conduced a house-to-house survey in a town in southern China and estimated that the prevalence of uveitis was 15.2/10,000 [10]. Two communitybased surveys, the Andhra Pradesh eye disease study and the Aravind comprehensive eye survey, estimated the prevalence of uveitis in southern India as 73/10,000 in urban Hyderabad city and 31/10,000 in rural Tamil Nadu $[11,12]$. The central Australian ocular health study estimated that the prevalence of anterior uveitis presenting in remote clinics of central Australia was 21/10,000, and the prevalence of posterior uveitis was 59/10,000 [13]. Hwang and Rim used nationwide health insurance databases to estimate the epidemiology of uveitis in Taiwan and South Korea. Their results indicated that the incidence of uveitis was 11.1/10,000 person-years and 10.6/10,000 person-years, and the prevalence was 19.4/10,000 and 17.3/10,000 in Taiwan and South Korea, respectively [14, 15]. Most results have shown that the prevalence of uveitis was higher in males than in females in these countries.

Causes of uveitis were usually categorized into three groups in the literature. In previous series, "noninfectious uveitis" referred to those uveitis with specific systemic or intraocular rheumatological diagnoses, "infectious uveitis" referred to those uveitis of which the pathogens have been identified. Uveitis of those the exact etiology or diagnosis could not be made were usually categorized as "idiopathic uveitis" or "uveitis with unidentified etiology". Generally, uveitis with idiopathic etiology was more common to be noninfectious. The distribution of uveitis etiologies varies in the Asia-Pacific region (Table 2). Uveitis is most commonly caused by noninfectious etiologies, except in Myanmar and Nepal, where noninfectious uveitis respectively represents 11 and $19 \%$ of cases; idiopathic uveitis represented 35 and $56 \%$, respectively $[16,17]$. Idiopathic uveitis represents the majority of uveitis cases in Bangladesh (47\%), South Korea (58\%), and Sri Lanka (65\%) [18-20]. In Australia, 42-45\% 
Table 2 Distribution of etiology and disease entities of uveitis in Asia-Pacific countries

\begin{tabular}{|c|c|c|c|c|c|c|c|c|}
\hline \multirow[t]{2}{*}{ Country } & \multirow[t]{2}{*}{ Period } & \multirow[t]{2}{*}{ Cases } & \multicolumn{2}{|l|}{ Etiology } & \multicolumn{4}{|c|}{ Specific disease entity $(\%)$} \\
\hline & & & Non-inf. & Idio. & Beh. & VKH & Sarc. & AS or B27 \\
\hline Australia [21] & 1980-1985 & 245 & $41.5 \%$ & $45.7 \%$ & 4.2 & 0.0 & 2.4 & 20.8 \\
\hline Australia [22] & 2009-2015 & 1165 & $45.2 \%$ & $33.4 \%$ & 2.1 & 1.8 & 6.7 & 22.7 \\
\hline Bangladesh [18] & 2009-2015 & 652 & N/A & $46.6 \%$ & 0.7 & 8.4 & 7.3 & 10.1 \\
\hline China [5] & 1996-2003 & 1752 & $52.1 \%$ & $44.8 \%$ & 16.5 & 15.9 & 0.2 & 3.3 \\
\hline China [40] & 2008-2011 & 199 & $41.2 \%$ & $50.8 \%$ & 10.1 & 9.5 & 0.0 & 2.0 \\
\hline China [6] & 2014-2015 & 606 & $54.8 \%$ & $38.9 \%$ & 15.3 & 20.6 & 0.8 & 5.1 \\
\hline India [33] & 1992 & 465 & $29.2 \%$ & $58.7 \%$ & 0.2 & 3.9 & 2.2 & 0.0 \\
\hline India [34] & 1996-2001 & 1233 & $34.3 \%$ & $51.2 \%$ & 1.9 & 3.6 & 0.2 & 6.5 \\
\hline India [35] & 1996-2001 & 8759 & $24.9 \%$ & $44.6 \%$ & 0.6 & 1.4 & 4.0 & 4.1 \\
\hline India [36] & 2012 & 343 & $44.6 \%$ & $26.2 \%$ & 0.0 & 2.9 & 9.3 & 16.9 \\
\hline India [37] & 2011-2014 & 1912 & $27.1 \%$ & $39.4 \%$ & 1.1 & 3.0 & 2.2 & 9. \\
\hline India [38] & 2013 & 352 & $33.5 \%$ & $33.0 \%$ & 0.3 & 6.0 & 6.8 & 10.8 \\
\hline India [39] & 2014 & 1123 & $25.7 \%$ & $38.6 \%$ & 0.4 & 4.9 & 4.6 & 4.5 \\
\hline Japan [7] & 1981-1994 & 551 & $63.1 \%$ & $30.7 \%$ & 27.9 & 10.3 & 18.1 & 2.6 \\
\hline Japan [32] & 1994-2003 & 1240 & $41.9 \%$ & $49.8 \%$ & 6.7 & 9.7 & 14.9 & 4.0 \\
\hline Japan [27] & 1999-2001 & 189 & $41.3 \%$ & $42.3 \%$ & 5.8 & 10.1 & 9.5 & N/A \\
\hline Japan [28] & 2003-2008 & 735 & N/A & N/A & 7.6 & 7.9 & 9.8 & 4.5 \\
\hline Japan [29] & 2009-2010 & 2556 & N/A & $49.8 \%$ & 3.9 & 7.0 & 10.6 & N/A \\
\hline Japan [31] & 2010-2012 & 695 & $43.9 \%$ & $38.0 \%$ & 4.6 & 4.0 & 8.1 & 0.1 \\
\hline Japan [30] & $2011-2015$ & 502 & $34.9 \%$ & $47.8 \%$ & 4.2 & 7.0 & 9.4 & 1.2 \\
\hline Myanmar [16] & 2013-2014 & 139 & $10.8 \%$ & $34.5 \%$ & 0.0 & 1.4 & 0.0 & 3.6 \\
\hline Nepal [17] & 2014 & 1113 & $19.4 \%$ & $56.4 \%$ & 0.4 & 1.8 & 1.7 & 6.6 \\
\hline New Zealand [23] & 2008-2014 & 1148 & $74.1 \% *$ & N/A & 1.6 & 1.0 & 5.0 & 28.7 \\
\hline Philippines [24] & 2010-2015 & 595 & $74.5 \% *$ & N/A & 1.3 & 9.2 & 0.0 & 0.0 \\
\hline Singapore [26] & 1997-2010 & 1249 & $42.6 \%$ & $24.9 \%$ & 1.8 & 8.7 & 1.4 & 18.7 \\
\hline Singapore [26] & 2014 & 148 & $33.1 \%$ & $30.4 \%$ & 1.4 & 5.4 & 4.7 & 13.5 \\
\hline South Korea [19] & 2013 & 602 & $24.8 \%$ & $58.1 \%$ & 7.1 & 2.3 & 2.7 & 8.8 \\
\hline Sri Lanka [20] & 2010-2014 & 750 & $18.7 \%$ & $64.7 \%$ & 1.2 & 1.3 & 6.0 & 3.3 \\
\hline Taiwan [44] & 1984-1986 & 240 & $83.3 \%$ & $10.0 \%$ & 17.9 & 9.2 & 0.4 & 45.8 \\
\hline Taiwan [45] & 1991-2000 & 160 & $46.9 \%$ & $38.1 \%$ & 8.8 & 16.3 & 2.5 & 16.3 \\
\hline Taiwan [46] & 2001-2014 & 450 & $57.3 \%$ & $26.4 \%$ & 3.8 & 10.4 & 2.7 & 24.9 \\
\hline Taiwan \& $[98]$ & 2009-2014 & 832 & N/A & N/A & 2.8 & N/A & 1.4 & 5.9 \\
\hline Thailand [41] & $2005-2006$ & 200 & $40.5 \%$ & $13.0 \%$ & 4.0 & 11.0 & 0.0 & 6.0 \\
\hline Thailand [8] & 2007-2012 & 446 & $38.3 \%$ & $48.4 \%$ & 6.7 & 22.4 & 0.0 & 2.0 \\
\hline Thailand [42] & 2010-2011 & 254 & $43.7 \%$ & $29.1 \%$ & 7.1 & 11.0 & 0.8 & 10.6 \\
\hline Thailand [43] & 2014-2015 & 758 & $41.0 \%$ & $16.5 \%$ & 5.7 & 13.5 & 1.2 & 12.4 \\
\hline Vietnam [25] & 2011-2015 & 212 & $36.3 \%$ & $36.3 \%$ & 6.6 & 14.2 & 3.3 & 1.9 \\
\hline
\end{tabular}

Non-Inf.: noninfectious; Idio.: idiopathic; Beh.: Behcet's disease; VKH: Vogt-Koyanagi-Harada disease; Sarc.: sarcoidosis; AS: ankylosing spondylitis; B27: human leukocyte antigen-B27; N/A: data not available;

*: including idiopathic etiology; ${ }^{\&}$ : only calculated when systemic involvement presented of uveitis cases were noninfectious, and 33-46\% were idiopathic [21, 22]. Studies in New Zealand and the Philippines have shown that infectious uveitis only represents a quarter of all cases [23, 24]. A report from Vietnam revealed similar proportions of idiopathic, infectious, and noninfectious uveitis [25].
Varying uveitis patterns have been found in many countries. For example, compared with patients before 2010, recent patients in Singapore showed a higher percentage of infectious uveitis [26]. Studies in Japan have revealed that $35-63 \%$ of uveitis cases were noninfectious, and $31-50 \%$ were idiopathic [7, 27-32]. These studies 
have also demonstrated that the patterns and specific entities of uveitis, including endophthalmitis, sarcoidosis, Bechet's disease, VKH disease, and anterior uveitis, have changed with time. Changing of the uveitis pattern has also been observed in India [33-39]. Studies have revealed a decrease in idiopathic uveitis and an increase in viral retinitis and tuberculosis-induced uveitis. Studies in China, Taiwan, and Thailand have revealed relatively consistent patterns of uveitis. Noninfectious uveitis represents $41-55 \%$ of cases in China and $38-44 \%$ in Thailand [5, 6, 8, 40-43]. It also represents the majority of uveitis cases in Taiwan, accounting for $47-83 \%$ of etiologies [44-46].

Generally, ankylosing spondylitis and human leukocyte antigen (HLA)-B27 are the most common etiologies of anterior uveitis in countries other than Japan. Study has reported that the prevalence of HLA-B27 positive population in Japan was as low as $0.4 \%$. On the other hand, VKH disease, Behcet's disease, and sarcoidosis are three major etiologies of intermediate, posterior, and panuveitis in Asia-Pacific countries.

\section{Behcet's disease}

Behcet's disease is a systemic inflammatory disorder in which oral ulcers, genital ulcers, and uveitis are the three main clinical features. The exact pathogenic mechanism of this disease remains unclear; however, genetic, infectious, and immunologic factors have been found to be strongly associated with it. The disease usually affects individuals aged between 20 and 40 years. Studies in Asia-Pacific countries have reported that $18-66 \%$ of patients have uveitis (Table 3) [47-59]. Interestingly, a decreasing trend in the prevalence of uveitis in Behcet's disease has been noticed in China, Japan, and Korea.

Ocular features of Behcet's disease in the acute stage include nongranulomatous anterior uveitis, vitreous haze, retinal hemorrhage or exudates, macular edema, and chorioretinitis (Fig. 1). The disease can be highly threatening to vision because final visual acuity can be worse than $20 / 200$ in $19-28 \%$ of patients $[60,61]$. The main causes of visual impairment in these patients were macular scar, optic nerve atrophy, and phthisis bulbi after multiple recurrences.

\section{Epidemiology of Behcet's disease in the Asia-Pacific region}

Although it could be found worldwide, the highest prevalence of Behcet's disease was found in the ancient silk road area that bridges Asia, the Middle East, and the Mediterranean. The incidence of Behcet's disease was
Table 3 Uveitis among patients with Behcet's disease in Asia-Pacific countries

\begin{tabular}{llll}
\hline Country & Year & Cases number & Uveitis \\
\hline Australia [47] & 2004 & 31 & $66.0 \%$ \\
China [48] & 2006 & 1996 & $34.8 \%$ \\
China [49] & 2012 & 334 & $26.4 \%$ \\
Hong Kong [47] & 2004 & 37 & $35.0 \%$ \\
India [50] & 1995 & 58 & $43.0 \%$ \\
Japan [51] & 2011 & 412 & $65.0 \%$ \\
Japan [52] & 2017 & 7950 & $37.3 \%$ \\
Japan [53] & 2018 & 3213 & $27.7 \%$ \\
South Korea [54] & 1997 & 1155 & $28.5 \%$ \\
South Korea [55] & 2001 & 1527 & $50.9 \%$ \\
South Korea [56] & 2014 & 3674 & $36.0 \%$ \\
Russia [57] & 2012 & 250 & $54.0 \%$ \\
Singapore [47] & 2004 & 37 & $41.0 \%$ \\
Taiwan [58] & 2018 & 236 & $18.2 \%$ \\
Thailand [59] & 2006 & 23 & $52.2 \%$ \\
\hline
\end{tabular}

reported as 0.4 cases per 10,000 person-years in South Korea and 0.2 cases per 10,000 person-years in Taiwan [58, 62]. The highest prevalence in the Asia-Pacific region has been reported in China at 14.0-110.0 out of 10,000, followed by Japan at 11.9-22.0, and South Korea at 3.3-3.6 [63-65]. However, Behcet's disease has seldom been diagnosed in Bangladesh, India, Myanmar, Nepal, New Zealand, the Philippines, Singapore, and Sri Lanka [16-18, 20, 23, 24, 26, 33-39]. Most reports have shown the disease to predominantly affect males, although in some countries female patients were more common [58].

Behcet's disease is a major cause of noninfectious uveitis in many Asia-Pacific countries. It represents $4 \%$ of all uveitis cases in Australia, 10-17\% in China, 4-28\% in Japan, 7\% in South Korea, 4-18\% in Taiwan, 4-7\% in Thailand, and 7\% in Vietnam [5-8, 19, 21, 25, 27-31, 4046]. Several studies have revealed that the incidence and severity of Behcet's disease-related uveitis have decreased with time $[66,67]$. The reason for this is unclear; changes in unknown environmental factors may be a possible explanation.

\section{Special circumstances in the Asia-Pacific region}

Despite that the prevalence and incidence was not the highest, Japan has been the focus of most studies of Behcet's disease. Many genetic factors and infectious and immunologic issues have been explored and discussed. Clinicians in countries other than Japan usually diagnose Behcet's disease based on the international study group criteria for Behcet's disease, whereas ophthalmologists in 


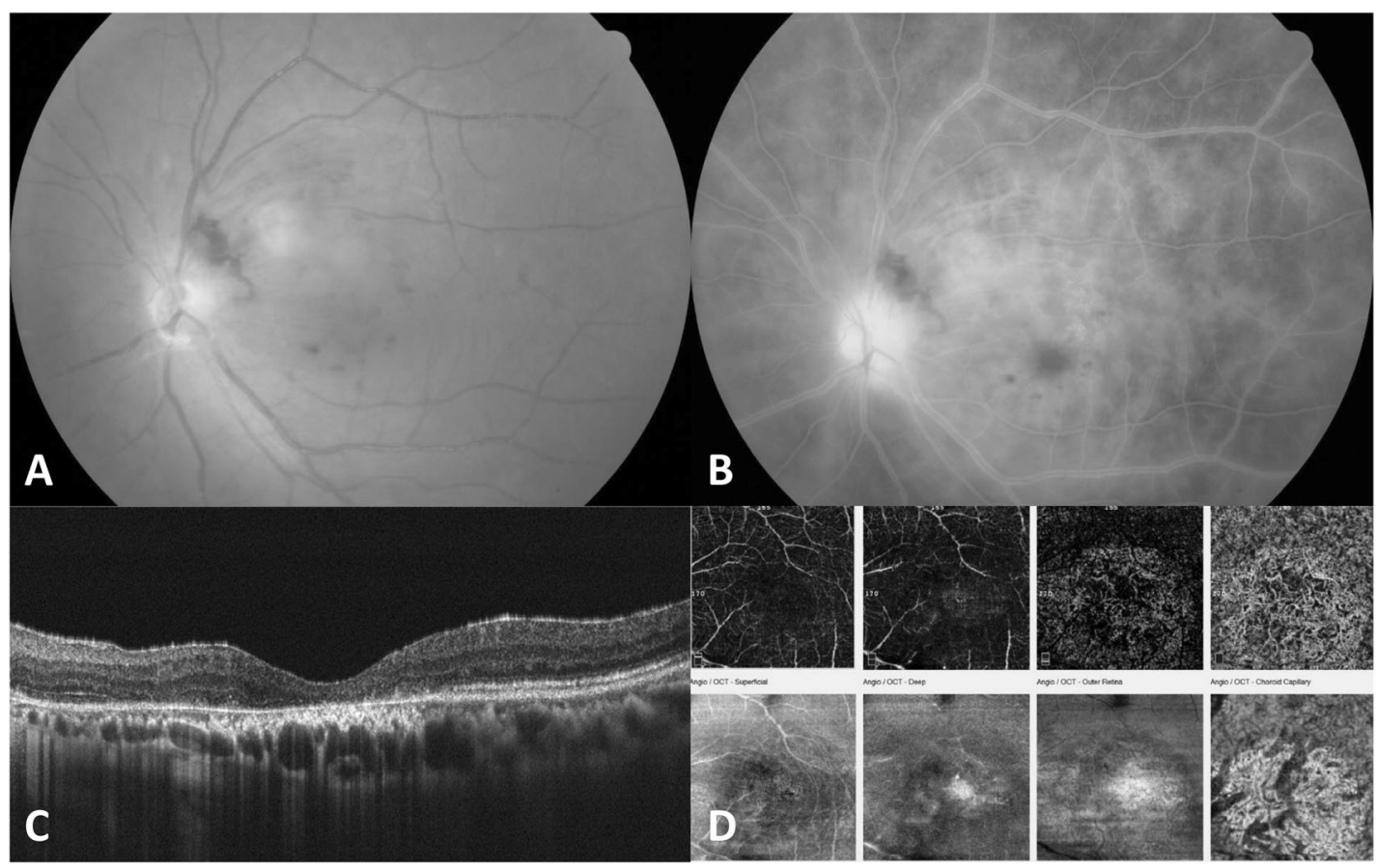

Fig. 1 A 46-year-old male had an acute attack of uveitis and was diagnosed with Behcet's disease. a Fundus photography showed retinal hemorrhage and choroiretinitis lesion near the macula in his left eye. b Fluorescein angiography revealed diffuse dye leakage from the retinal capillary and optic nerve in a "fern-like pattern". Macular edema was also observed. c Eight years after the initial attack, optical coherence tomography showed a macular scar with disruption of the ellipsoid zone. d Optical coherence tomographic angiogram eventually disclosed ischemic change and enlargement of the foveal avascular zone
Japan usually diagnose based on the criteria proposed by the Japanese Research committee [68] (Table 4). An ocular attack score specific to Behcet's disease was also developed for monitoring severity and predicting the outcome of patients with uveitis [69].

The treatment strategy for Behcet's disease in Japan also differs from the recommendation made by the European League against Rheumatism, which suggests that systemic corticosteroids be used in combination with other immunomodulatory agents. Systemic corticosteroids are not suggested for Behcet's patients in Japan since studies have found that long-term steroid therapy may result in poor visual outcome and uveitis may frequently recur during tapering [70]. Systemic infusion of infliximab is usually prescribed if the inflammation cannot be controlled by colchicine or cyclosporine. Japan is one of the first countries where biologic immunomodulatory agents were approved and funded for treating uveitis. Many Japanese studies have proven its effectiveness in decreasing inflammation for cases of Behcet's uveitis [70]. Using infliximab may not only reduce the frequency of uveitis flare-ups but also alleviate the signs of vasculitis and dye leakage in fluorescence angiography. Alternatively, adalimumab has been approved for treating noninfectious uveitis, including Behcet's disease-associated uveitis, in many countries including South Korea and Taiwan.

\section{Sarcoidosis}

\section{Epidemiology and clinical manifestations}

Sarcoidosis is a systemic granulomatous disease that affects various organs. The exact immunopathogenesis remains elusive. Genetic factors and pathogenic participation may both play roles. Overall, 30-70\% of patients with systemic sarcoidosis may be affected by uveitis during the clinical course [71, 72]. Western literature generally shows that 3-10\% of uveitis cases are associated with sarcoidosis. In the Asia-Pacific region, sarcoidosis accounts for 1.5-14.9\% of all uveitis cases (Table 5). In general, sarcoidosisassociated uveitis is characterized by bilateral anterior or posterior granulomatous inflammation in a relapsing or recurring pattern. In the anterior segment, anterior uveitis with iris nodules or mutton-fat keratic precipitates is commonly seen. In the vitreous cavity, vitritis and haze with snowballs are classical presentations (Fig. 2a). Posterior findings typically include active and atrophic peripheral chorioretinal granulomas and periphlebitis (Fig. 2b, c).

The prevalence of sarcoidosis is influenced by multiple factors. For example, studies have indicated that Japanese populations are more susceptible to ocular involvement (50-93.5\%) compared with populations from other countries $(23-60 \%)$ [71, 73-75]. This can be attributed to 


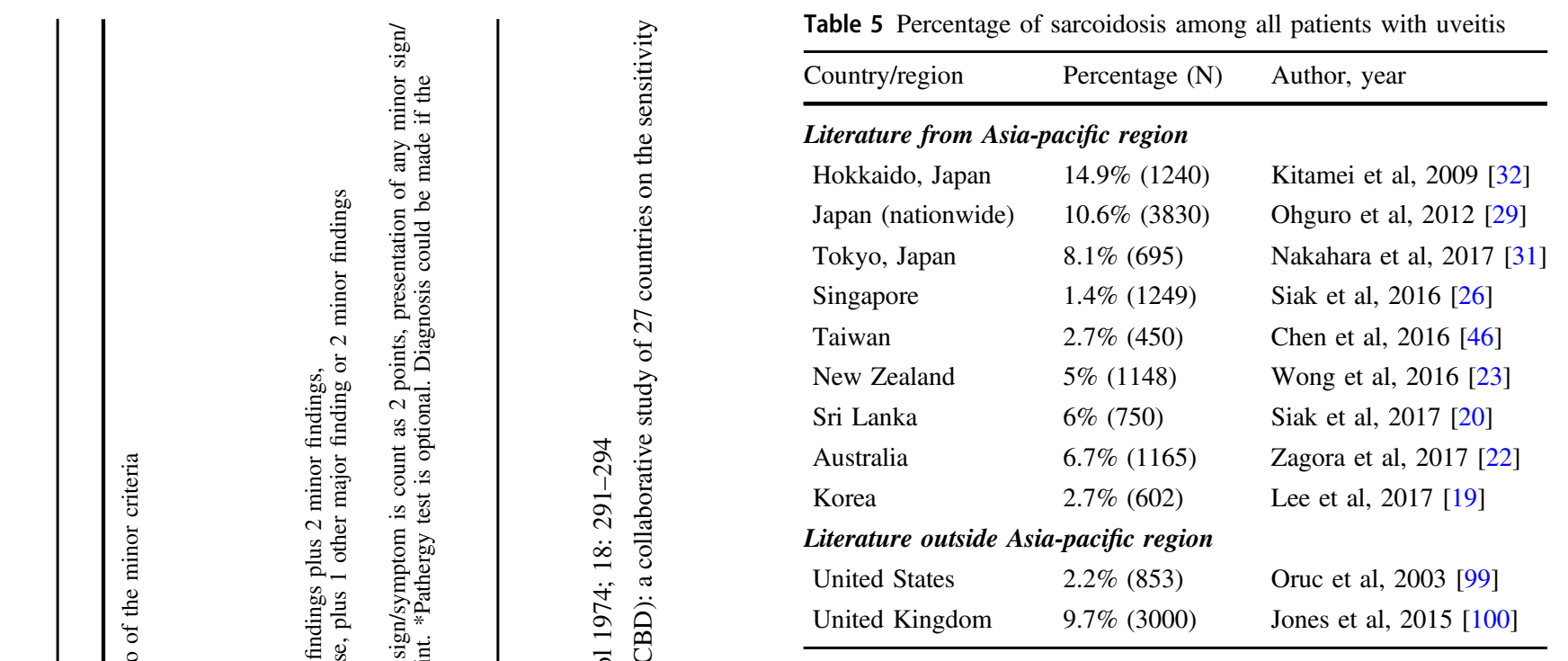

ethnicity, environmental factors, and possibly the availability of surveillance tools. Physicians in Japan are highly aware of this disease, because sarcoidosis is the most common entity in uveitis [29]. Ancillary tests for angiotensin-converting enzyme or serum-soluble interleukin 2 receptor (sIL-2R) are readily available in Japan. These factors may all contribute to the final diagnosis.

\section{Diagnostic criteria for ocular sarcoidosis}

No single clinical or laboratory diagnostic biomarker for sarcoidosis exists. Therefore, a collaboration of uveitis specialists from four continents (Asia, Africa, Europe, and North America) created the international workshop on ocular sarcoidosis diagnostic criteria for sarcoidosis [76]. Takase et al. performed a case-control study recruiting 50 biopsy-proven sarcoidosis cases and 320 control patients with other uveitis etiologies in Japan, and the sensitivity, specificity, positive predictive value, and negative predictive value of the criteria were $1.00,0.96,0.78$, and 1.00 , respectively [77]. Acharya et al. studied an international cohort with 884 cases from 12 countries. Of the 264 cases suspected to have ocular sarcoidosis, 97 (37\%) did not meet the criteria. These results suggested that the sensitivity of this proposed criteria is more applicable to Asia-Pacific region, especially the Japanese population, because its criteria were based on the clinical data of many Japanese patients [78].

\section{Studies regarding the immunopathogenesis of sarcoidosis}

Studies increasingly suggest that the immunopathogenesis of sarcoidosis is highly associated with environmental and 


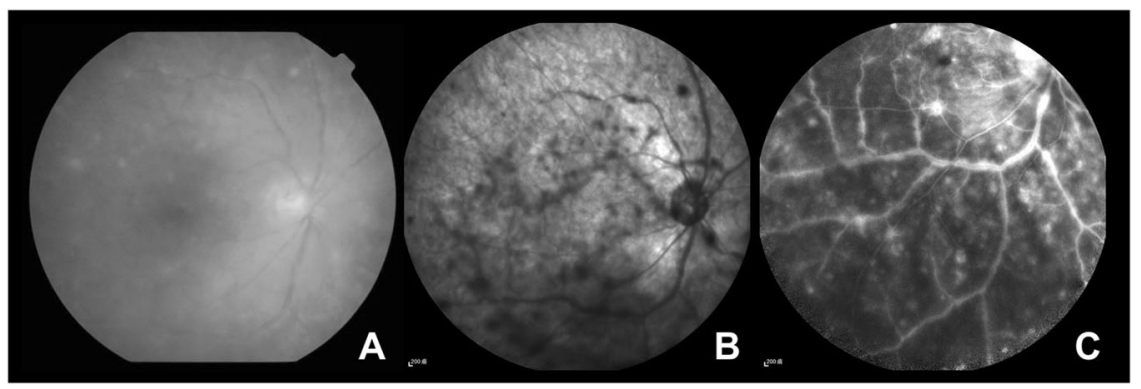

Fig. 2 A 67-year-old female with sarcoid uveitis presented with bilateral panuveitis, mutton-fat keratic precipitates, iris nodules, and vitreous snowballs. Elevation of serum angiotensin-convertingenzyme level and bilateral hilar lymphadenopathy were noted. a Fundus photography revealed vitreous haze with multiple yellowish

infectious factors. Propionibacterium species and Mycobacterium tuberculosis have long been suspected to be the initial trigger of the disease. Abe et al. identified Propionibacterium acnes in $77.5 \%$ of sarcoid lymph nodes, compared with $21.1 \%$ found in nonsarcoid tissues [79]. Yamada et al. revealed that the mean signal counts of $P$. acnes DNA were significantly higher in granulomatous areas than that in nongranulomatous areas in sarcoid lymph nodes [80]. Other studies have confirmed this finding[81],.

Because hilar or mediastinal lymphadenopathy is one of the hallmarks of sarcoidosis, it is reasonable to suppose that the triggering microorganism enters the human body through the respiratory tract. Research on animals revealed that inadequate response of toll-like receptor 2 to the pathogen (such as deficient myeloid differentiation primary response protein 88 (MyD88) activity) might result in impaired bacterial clearance [82]. In this case, subsequent systemic spread of the pathogen via the bloodstream results in the involvement of multiple organs. Intracellular proliferation of $P$. acnes in macrophages triggers T-helper cell hypersensitivity and granuloma formation. Aberrant aggregation of serum amyloid A within granulomas and cascades of cytokines (e.g., interferon- $\gamma$, interleukin-2, and TNF- $\alpha$ ) promotes chronic granulomatous inflammation such as sarcoidosis [83].

\section{Treatment}

In general, the treatment of sarcoid uveitis follows the general stepladder approach in noninfectious uveitis. As the disease responds favorably to steroid treatment, in isolated iridocyclitis with minimal intermediate or posterior segment involvement, topical steroid could suffice to control the disease. In cases of panuveitis, however, systemic therapy should be administered, with a starting dose of $0.5 \sim 1 \mathrm{mg} /$ $\mathrm{kg}$ per day and gradual tapering. In cases of asymmetric presentation, or with systemic comorbidities, local steroid deep chorioretinal nodular lesions. b Vitreous opacity was clearly shown on infrared imaging. c Segmental phlebitis with leakage and multiple choroidal hyperfluorescent spots were revealed on fluorescein angiogram

injection can be considered, including subtenon/orbital floor injection of triamcinolone, or intravitreal injection of dexamethasone implant. In cases with refractory or persistent relapsing-remitting courses, traditional immunosuppressive agents should be applied. Antimetabolites (methotrexate, azathioprine, or mycophenolate) or calcineurin inhibitors (cyclosporine or tacrolimus) can be administered as a single agent or as combined usage [2].

If the traditional treatment failed to achieve favorable clinical response, further escalated management with biologics should be considered. Anti-TNF- $\alpha$ agent is the first choice of biologics for ocular sarcoidosis. Two recent pivotal multinational phase 3 trials established the effectiveness of adalimumab (a fully humanized monoclonal antibody) in treating noninfectious uveitis. In VISUAL 1 study, 18 subjects with active sarcoid uveitis responded to adalimumab, with a 50\% reduction in experiencing treatment failure than the placebo group [3, 84]. In VISUAL 2 trial, 229 inactive uveitis cases (including 32 cases with sarcoidosis) were investigated. Adalimumab administration also showed a significant prolonged time to treatment failure [4].

\section{VKH disease}

\section{Introduction and clinical features}

VKH disease is a multisystemic disorder characterized by bilateral granulomatous panuveitis with exudative retinal detachments from inflammation of the choroid (Fig. 3). VKH disease occurs more commonly in patients with a genetic predisposition to the disease, including those from Asian, Middle Eastern, Hispanic, and Native American populations, but not blacks of sub-Saharan African descent. This suggests that risk factors of VKH disease do not depend on skin pigmentation alone. T-cell-mediated 


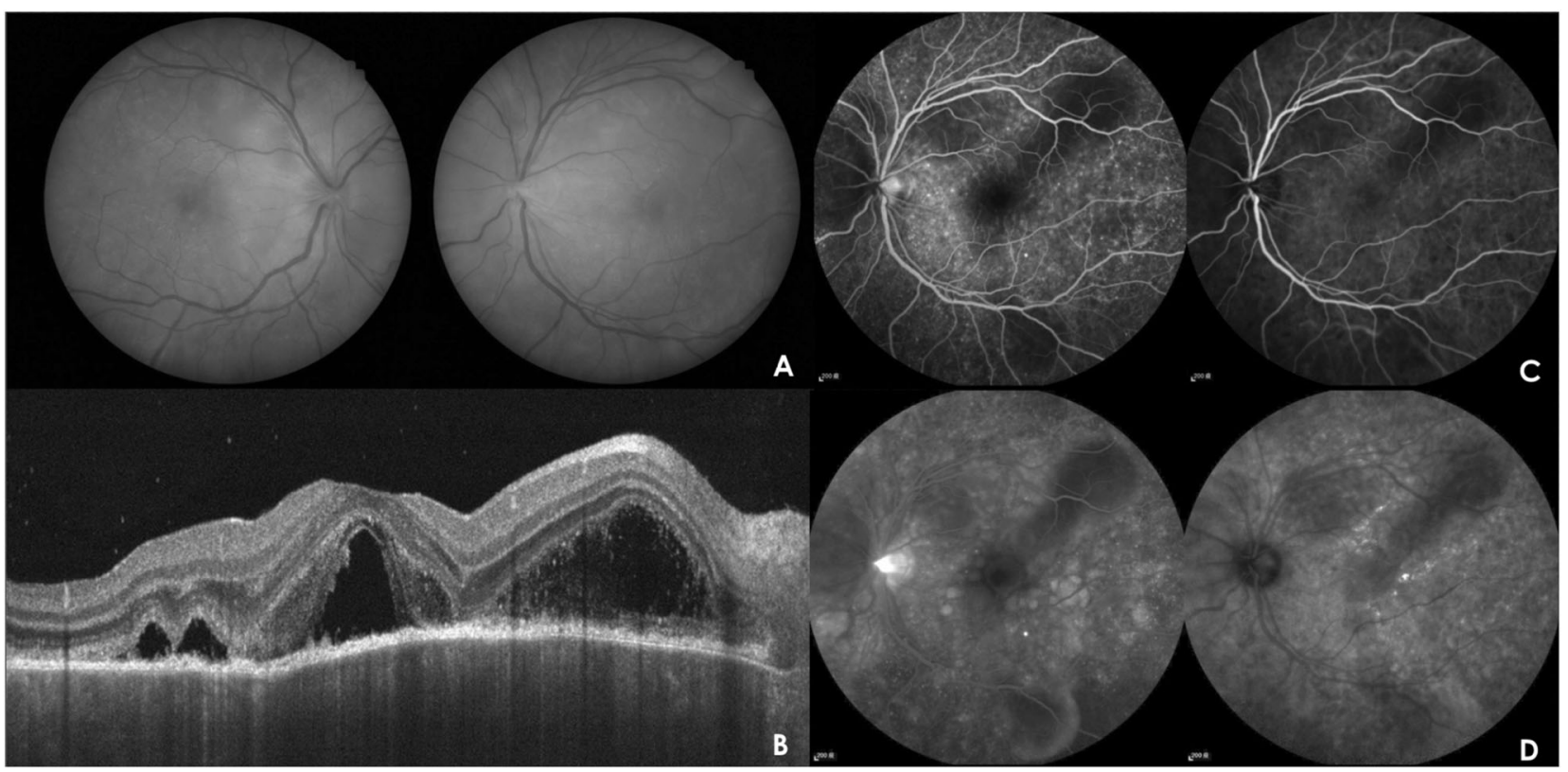

Fig. 3 A 23-year-old male patient with Vogt-Koyanagi-Harada disease. a Color fundus photographs revealed bilateral multifocal exudative retinal detachment with disc hyperemia. b Optical coherence tomography showed subretinal fluid divided into multiple compartments by septa formed by inflammation. c Mid-phase fluorescein angiography (FA) demonstrated multifocal pinpoint leakage with classic "starry sky" appearance. Indocyanine green angiography (ICGA) showed hypofluorescent dark spots as well as choroidal vessel leakage. d Late-phase FA and ICGA revealed pooling of dye with large placoid areas of hyperfluorescence autoimmune responses against antigenic components of melanocytes and melanocyte-associated antigens are thought to be the main driving forces of the disease.

Systemic symptoms of VKH disease include headache, orbital pain, fever, nausea, meningism, vertigo, and tinnitus. These symptoms usually precede the onset of ocular disease by a few days and are followed by an acute uveitic phase that may last for weeks. The hallmark ocular presentation in the acute phase is bilateral exudative retinal detachment. The convalescent stage follows several months after the first episode of ocular inflammation, with developing signs of depigmentation of the eye and skin. Sunset-glow fundus changes representing choroidal depigmentation exhibiting bright orange-red reflex are more common in Asians. Perilimbal depigmentation can be observed in up to $85 \%$ of Japanese patients, whereas Caucasians and other nonJapanese patients with VKH disease, such as Singaporean [85] and Chinese patients [86], rarely develop the sign. The diagnostic criteria for VKH disease are based on clinical findings of ocular and extraocular manifestations. However, cerebrospinal fluid analysis is more commonly performed to confirm the diagnosis in Japan than in other countries.

\section{Epidemiology}

VKH disease has worldwide distribution but a predilection for darkly pigmented peoples, particularly those with Asian, Middle Eastern, Hispanic, and Native American ancestry.
Table 6 Percentage of Vogt-Koyanahi-Harada disease among all uveitis

\begin{tabular}{lll}
\hline Country/region & Percentage (N) & Author, year \\
\hline China & $15.9 \%(1752)$ & Yang et al, 2005 [5] \\
Southern Vietnam & $14 \%(212)$ & Nguyen et al, 2017 [25] \\
Thailand & $13.5 \%(758)$ & Sukavatcharin et al, 2017 [43] \\
Taiwan & $10.4 \%(450)$ & Chen et al, 2016 [46] \\
Hokkaido, Japan & $9.7 \%(1240)$ & Kitamei et al, 2009 [32] \\
Philippines & $9.2 \%(595)$ & Abano et al, 2017 [24] \\
Singapore & $8.7 \%(1249)$ & Siak et al, 2016 [26] \\
Japan (nationwide) & $7.0 \%(3830)$ & Ohguro et al, 2012 [29] \\
South India & $4.3 \%(1123)$ & Sabhapandit et al, 2017 [39] \\
Tokyo, Japan & $4.0 \%(695)$ & Nakahara et al, 2017 [31] \\
North India & $3.0 \%(1912)$ & Dogra et al, 2017 [37] \\
South Korea & $2.3 \%(602)$ & Lee et al, 2017 [19] \\
Australia & $1.8 \%(1165)$ & Zagora et al, 2017 [22] \\
Sri Lanka & $1.3 \%(750)$ & Siak et al, 2017 [20] \\
New Zealand & $1 \%(1148)$ & Wong et al, 2016 [23] \\
\hline
\end{tabular}

VKH disease is less common in countries where Caucasian populations are predominant (Table 6). In a retrospective chart review conducted in a tertiary hospital in China, VKH disease was the second most common identifiable cause of uveitis (15.9\%), with the first being Behcet's disease [5]. Southern Vietnam also has a preponderant population of patients with VKH disease (14\%), and VKH disease was 
the most frequently identified cause of noninfectious uveitis in that region [25]. A review of the literature on the epidemiology of uveitis in the Asia-Pacific region indicates that China has the highest frequency of VKH disease among countries in the region. This is followed by Vietnam, Taiwan, Hokkaido (Japan), the Philippines, Singapore, and New Zealand, where VKH disease only contributes to $1 \%$ of uveitis cases (Table 1). The frequency of VKH disease as diagnosed uveitis in tertiary centers may be changing. A study from Tokyo University Hospital indicated a decrease in patients with VKH disease from $6.3 \%$ in 2004-2006 to $4 \%$ in 2010-2012. The authors attributed this finding to the increase in optical coherence tomography in communitybased clinics, making diagnosis easier and allowing more patients to be treated rather than referred to university hospital-based clinics [31].

Gender predilection of VKH disease seems to vary globally. Studies from the Philippines and India have suggested that women are affected more frequently than men, whereas men and women are equally represented in other studies from the Asia-Pacific region [24, 25, 43, 85].

\section{VKH disease research in the Asia-Pacific region}

Because VKH disease is an inflammatory disease affecting mainly the choroid, extensive research has focused on the evaluation of choroidal ultrastructural changes before, during, and after treatment of the disease. The advent of multimodal imaging and especially enhanced depth imaging optical coherence tomography (OCT) has improved the understanding of this challenging illness. Fong et al. first used OCT in 2011 to evaluate the structural changes of the choroid in patients with $\mathrm{VKH}$ disease and found loss of inner choroidal focal hyperreflectivity [87]. Nakayama et al. used OCT to reveal decreasing choroidal thickness with high-dose corticosteroid treatment and suggested that choroidal thickness as measured by OCT may serve as a marker for the degree of choroidal inflammation in acute VKH disease [88]. OCT can also be a useful tool for detecting latent choroidal inflammation in $\mathrm{VKH}$ disease in eyes with remission subfoveal choroidal thickness greater than 240 microns. Tagawa et al. noted the choroid in eyes of patients with VKH disease thickened significantly prior to anterior segment recurrence [89].

Novel parameters derived from OCT may provide further insights. The luminal/stromal ratio as measured by binarization of OCT images was found to be a predictive factor for the progression of peripapillary atrophy, subsequent chronic recurrences, and total dose of corticosteroid, thus serving as a marker for the degree of choroidal inflammation in VKH disease [90]. Moreover, pathological changes of $\mathrm{VKH}$ disease can be evaluated through polarizationsensitive OCT to document in vivo the choroidal melanin loss in chronic VKH disease [91]. The definitive pathophysiology of VKH disease remains elusive, and further research is warranted to understand the immunogenetic and infectious basis of the disease.

\section{Therapy}

Early treatment with systemic high dose corticosteroid remains essential to the treatment of acute VKH disease. Systemic corticosteroid treatment should be tapered off slowly and the duration of the treatment should be greater than 6 months for the treatment of acute VKH in order to decrease the risk of recurrence manifested as exudative retinal detachment, and to improve final visual acuity [92, 93].

Park et al. investigated whether route of corticosteroid administration during the acute stage of $\mathrm{VKH}$ disease affects depigmentary change as determined by Sunset-glow fundus scores and subfoveal choroidal thickness (SCT) during the convalescent stage [94]. Compared to oral administration of prednisolone with the initial dosage of $0.8-1.0 \mathrm{mg} / \mathrm{kg} /$ day for at least 2 weeks, intravenous infusion of methylprednisolone $1 \mathrm{~g} /$ day for 3 days initially resulted in less depigmentary changes and greater SCT during the convalescent stage. In addition to corticosteroids, immunosuppressive agents such as cyclosporine A, methotrexate, azathioprine, mycophenolate mofetil, and alkylating agents have been used successfully to treat VKH. The international uveitis study group and the American uveitis society have recommended treatment of VKH with immunosuppressive agents necessary in order to decrease recurrences [95].

In challenging cases with poor treatment response to corticosteroids and immunosuppressive agents, biologic agents such as adalimumab, rituximab, and infliximab have been shown to be effective in these cases [96, 97]. These biologic agents provide a quick and effective way to suppress the intraocular inflammation and increase the possibility of tapering systemic corticosteroid. Nevertheless, reactivation of tuberculosis is a possible side effect when the patients were treated with Anti-TNF- $\alpha$ agents. Screening of systemic tuberculosis should always be performed prior to these anti-TNF therapy.

\section{Summary}

Noninfectious uveitis represents a large proportion of all uveitis in Asia-Pacific countries. The distribution of patterns and entities of uveitis vary with genetic, ethnic, environmental, and cultural factors. This review finds that the variation exists not only between countries but also times and locations within countries. Nevertheless, Behcet's 
disease, sarcoidosis, and VKH disease remain the three of the most common causes of noninfectious uveitis in Asia-Pacific countries. Many studies of these diseases have been conducted in this region. Although the understanding of these diseases has improved recently, the exact mechanism and immune pathogenesis of these diseases remain unclear. A collaborative study exploring genetic and environmental factors, pathogenesis, and treatments of specific disease entities might improve knowledge and patient outcomes in the future.

Acknowledgements This work was supported by Taipei Veterans General Hospital (106 107;V107B-019) This manuscript was edited by Wallace Academic Editing

\section{Compliance with ethical standards}

Conflict of interest The authors declare that they have no conflict of interest.

\section{References}

1. Rothova A, Suttorp-van Schulten MS, Frits Treffers W, Kijlstra A. Causes and frequency of blindness in patients with intraocular inflammatory disease. Br J Ophthalmol. 1996;80:332-6.

2. Dick AD, Rosenbaum JT, Al-Dhibi HA, Belfort R Jr., Brezin AP, et al. Guidance on noncorticosteroid systemic immunomodulatory therapy in noninfectious uveitis: fundamentals of care for uveitis (FOCUS) Initiative. Ophthalmology. 2018;125:757-73.

3. Jaffe GJ, Dick AD, Brezin AP, Nguyen QD, Thorne JE, Kestelyn $\mathrm{P}$, et al. Adalimumab in patients with active noninfectious uveitis. N Engl J Med. 2016;375:932-43.

4. Nguyen QD, Merrill PT, Jaffe GJ, Dick AD, Kurup SK, Sheppard $\mathrm{J}$, et al. Adalimumab for prevention of uveitic flare in patients with inactive non-infectious uveitis controlled by corticosteroids (VISUAL II): a multicentre, double-masked, randomised, placebo-controlled phase 3 trial. Lancet. 2016;388:1183-92.

5. Yang P, Zhang Z, Zhou H, Li B, Huang X, Gao Y, et al. Clinical patterns and characteristics of uveitis in a tertiary center for uveitis in China. Curr Eye Res. 2005;30:943-8.

6. Gao F, Zhao C, Cheng G, Pei M, Liu X, Wang M, et al. Clinical patterns of uveitis in a tertiary center in north China. Ocul Immunol Inflamm. 2017;25(sup1):S1-S7.

7. Kotake S, Furudate N, Sasamoto Y, Yoshikawa K, Goda C, Matsuda H. Characteristics of endogenous uveitis in Hokkaido, Japan. Graefes Arch Clin Exp Ophthalmol. 1996;234:599-603.

8. Silpa-Archa S, Noonpradej S, Amphornphruet A. Pattern of uveitis in a referral ophthalmology center in the central district of Thailand. Ocul Immunol Inflamm. 2015;23:320-8.

9. Nakao K, Ohba N. [Prevalence of endogenous uveitis in Kagoshima Prefecture, Southwest Japan]. Nippon Ganka Gakkai Zasshi. 1996;100:150-5.

10. Hu SXC, Yang P, Huang X An epidemiological survey of uveitis in Southern China. 2002; 2: 1-3.

11. Dandona L, Dandona R, John RK, McCarty CA, Rao GN. Population based assessment of uveitis in an urban population in southern India. Br J Ophthalmol. 2000;84:706-9.
12. Rathinam SR, Krishnadas R, Ramakrishnan R, Thulasiraj RD, Tielsch JM, Katz J, et al. Population-based prevalence of uveitis in southern India. Br J Ophthalmol. 2011;95:463-7.

13. Chang JH, Landers J, Henderson TR, Craig JE. Prevalence of uveitis in indigenous populations presenting to remote clinics of central Australia: the central Australian ocular health study. Clin Exp Ophthalmol. 2012;40:448-53.

14. Hwang DK, Chou YJ, Pu CY, Chou P. Epidemiology of uveitis among the chinese population in Taiwan: a population-based study. Ophthalmology. 2012;119:2371-6.

15. Rim TH, Kim SS, Ham DI, Yu SY, Chung EJ, Lee SC, et al. Incidence and prevalence of uveitis in South Korea: a nationwide cohort study. Br J Ophthalmol. 2018;102:79-83.

16. Win MZA, Win T, Myint S, Shwe T, Sandar H. Epidemiology of uveitis in a tertiary eye center in Myanmar. Ocul Immunol Inflamm. 2017;25(sup1):S69-S74.

17. Manandhar A. Patterns of uveitis and scleritis in Nepal: a tertiary referral center study. Ocul Immunol Inflamm. 2017;25(sup1): S54-S62.

18. Rahman Z, Ahsan Z, Rahman NA, Dutta Majumder P Pattern of uveitis in a referral hospital in Bangladesh. Ocul Immunol Inflamm 2018;26:893-896.

19. Lee JY, Kim DY, Woo SJ, Kim TW, Kim SJ, Lee CS, et al. Clinical patterns of uveitis in tertiary ophthalmology centers in Seoul, South Korea. Ocul Immunol Inflamm. 2017;25(sup1): S24-S30.

20. Siak J, Kumaradas M, Chee SP. The pattern of uveitis in Sri Lanka. Ocul Immunol Inflamm. 2017;25(sup1):S63-S68.

21. Wakefield D, Dunlop I, McCluskey PJ, Penny R. Uveitis: aetiology and disease associations in an Australian population. Aust N Z J Ophthalmol. 1986;14:181-7.

22. Zagora SL, Symes R, Yeung A, Yates W, Wakefield D, McCluskey PJ. Etiology and clinical features of ocular inflammatory diseases in a tertiary referral centre in Sydney, Australia. Ocul Immunol Inflamm. 2017;25(sup1):S107-14.

23. Wong A, McKelvie J, Slight C, Sims J. Land of the long white cloud: the spectrum of uveitis at a tertiary referral center in New Zealand. Ocul Immunol Inflamm. 2017;25(sup1):S115-S121.

24. Abano JM, Galvante PR, Siopongco P, Dans K, Lopez J. Review of epidemiology of uveitis in Asia: pattern of uveitis in a tertiary hospital in the Philippines. Ocul Immunol Inflamm. 2017;25 (sup1):S75-S80.

25. Nguyen M, Siak J, Chee SP, Diem VQH. The spectrum of uveitis in southern Vietnam. Ocul Immunol Inflamm. 2017;25 (sup1):S100-S106.

26. Siak J, Jansen A, Waduthantri S, Teoh CS, Jap A, Chee SP. The pattern of uveitis among chinese, malays, and indians in Singapore. Ocul Immunol Inflamm. 2017;25(sup1):S81-93.

27. Wakabayashi T, Morimura Y, Miyamoto Y, Okada AA. Changing patterns of intraocular inflammatory disease in Japan. Ocul Immunol Inflamm. 2003;11:277-86.

28. Hikita S, Sonoda KH, Hijioka K, Fujimoto T, Ito T, Ishibashi T. [Incidence of uveitis in the northern Kyushu region of Japan --comparison between the periods of 1996-2001 and 2003-8]. Nippon Ganka Gakkai Zasshi. 2012;116:847-55.

29. Ohguro N, Sonoda KH, Takeuchi M, Matsumura M, Mochizuki M. The 2009 prospective multi-center epidemiologic survey of uveitis in Japan. Jpn J Ophthalmol. 2012;56:432-5.

30. Takahashi R, Yoshida A, Inoda S, Okubo A, Kawashima H. Uveitis incidence in Jichi medical university hospital, Japan, during 2011-5. Clin Ophthalmol. 2017;11:1151-6.

31. Nakahara H, Kaburaki T, Tanaka R, Takamoto M, Ohtomo K, Karakawa A, et al. Frequency of uveitis in the central Tokyo area (2010-2). Ocul Immunol Inflamm. 2017;25(sup1):S8-S14. 
32. Kitamei H, Kitaichi N, Namba K, Kotake S, Goda C, Kitamura $\mathrm{M}$, et al. Clinical features of intraocular inflammation in Hokkaido, Japan. Acta Ophthalmol. 2009;87:424-8.

33. Das D, Biswas J, Ganesh SK. Pattern of uveitis in a referral uveitis clinic in India. Indian J Ophthalmol. 1995;43:117-21.

34. Singh R, Gupta V, Gupta A. Pattern of uveitis in a referral eye clinic in north India. Indian J Ophthalmol. 2004;52:121-5.

35. Rathinam SR, Namperumalsamy P. Global variation and pattern changes in epidemiology of uveitis. Indian $\mathrm{J}$ Ophthalmol. 2007;55:173-83.

36. Das D, Bhattacharjee H, Das K, Tahiliani PS, Bhattacharyya P, Bharali $\mathrm{G}$, et al. The changing patterns of uveitis in a tertiary institute of northeast India. Indian J Ophthalmol. 2015;63:735-7.

37. Dogra M, Singh R, Agarwal A, Sharma A, Singh SR, Gautam N, et al. Epidemiology of uveitis in a tertiary-care referral institute in north India. Ocul Immunol Inflamm. 2017;25(sup1):S46-S53.

38. Biswas J, Kharel Sitaula R, Multani P. Changing uveitis patterns in south India - comparison between two decades. Indian $\mathbf{J}$ Ophthalmol. 2018;66:524-7.

39. Sabhapandit S, Murthy SI, Singh VM, Gaitonde K, Gopal M, Marsonia K, et al. Epidemiology and clinical features of uveitis from urban populations in south India. Ocul Immunol Inflamm. 2017;25(sup1):S39-45.

40. Zheng Y, Zhang LX, Meng QL, Zhang M, Cui Y, Liu QY, et al. Clinical patterns and characteristics of uveitis in a secondary hospital in southern China. Int J Ophthalmol. 2015;8:337-41.

41. Pathanapitoon K, Kunavisarut P, Ausayakhun S, Sirirungsi W, Rothova A. Uveitis in a tertiary ophthalmology centre in Thailand. Br J Ophthalmol. 2008;92:474-8.

42. Sittivarakul W, Bhurayanontachai P, Ratanasukon M. Pattern of uveitis in a university-based referral center in southern Thailand. Ocul Immunol Inflamm. 2013;21:53-60.

43. Sukavatcharin S, Kijdaoroong O, Lekhanont K, Arj-Ong Vallipakorn S. Pattern of uveitis in a tertiary ophthalmology center in Thailand. Ocul Immunol Inflamm. 2017;25(sup1):S94-99.

44. Chung YM, Yeh TS, Liu JH. Endogenous uveitis in Chinese--an analysis of 240 cases in a uveitis clinic. Jpn J Ophthalmol. 1988;32:64-9.

45. Chou LC, Sheu SJ, Hong MC, Hsiao YC, Wu TT, Chuang CT, et al. Endogenous uveitis: experiences in Kaohsiung veterans general hospital. J Chin Med Assoc. 2003;66:46-50.

46. Chen SC, Chuang CT, Chu MY, Sheu SJ. Patterns and etiologies of uveitis at a tertiary referral center in Taiwan. Ocul Immunol Inflamm. 2017;25(sup1):S31-38.

47. Fereydoun D, Farhad S, Ashok K, Kuang CY, Tak CC, Andrea B. Comparative analysis of Behcet's disease in the APLAR region. APLAR J Rheumatol. 2004;7:38-43.

48. Zhuoli Z, Jinmin P, Xiaomeng H, Yi D. Clinical manifestations of Behcet's disease in chinese patients. APLAR J Rheumatol. 2006;9:244-7.

49. Zhang Z, He F, Shi Y. Behcet's disease seen in China: analysis of 334 cases. Rheumatol Int. 2013;33:645-8.

50. Pande I, Uppal SS, Kailash S, Kumar A, Malavtya AN. Behçet's disease in India: aclinical, immunological, immunogenetic and outcome study. Rheumatology. 1995;34:825-30.

51. Ideguchi H, Suda A, Takeno M, Ueda A, Ohno S, Ishigatsubo Y. Behcet disease: evolution of clinical manifestations. Med (Baltim). 2011;90:125-32.

52. Ishido $\mathrm{T}$, Horita $\mathrm{N}$, Takeuchi $\mathrm{M}$, Kawagoe $\mathrm{T}$, Shibuya $\mathrm{E}$, Yamane $\mathrm{T}$, et al. Clinical manifestations of Behcet's disease depending on sex and age: results from Japanese nationwide registration. Rheumatol (Oxf). 2017;56:1918-27.

53. Suwa A, Horita N, Ishido T, Takeuchi M, Kawagoe T, Shibuya E et al. The ocular involvement did not accompany with the genital ulcer or the gastrointestinal symptoms at the early stage of
Behcet's disease. Mod Rheumatol 2018: 1-6. https://doi.org/10. 1080/14397595.2018.1457424. [Epub ahead of print]

54. Bang D, Yoon KH, Chung HG, Choi EH, Lee ES, Lee S. Epidemiological and clinical features of Behcet's disease in Korea. Yonsei Med J. 1997;38:428-36.

55. Bang D, Lee JH, Lee ES, Lee S, Choi JS, Kim YK, et al. Epidemiologic and clinical survey of Behcet's disease in Korea: the first multicenter study. J Korean Med Sci. 2001;16:615-8.

56. Kim DY, Choi MJ, Cho S, Kim DW, Bang D. Changing clinical expression of Behcet disease in Korea during three decades (1983-2012): chronological analysis of 3674 hospital-based patients. Br J Dermatol. 2014;170:458-61.

57. Lennikov A, Alekberova Z, Goloeva R, Kitaichi N, Denisov L, Namba K, et al. Single center study on ethnic and clinical features of Behcet's disease in Moscow, Russia. Clin Rheumatol. 2015;34:321-7.

58. Lin YH, Tai TY, Pu CY, Hwang DK, Chung YM, Chou YJ. Epidemiology of Behcet's disease in Taiwan: a population-based study. Ophthalmic Epidemiol. 2018;25:323-9.

59. Arromdee E, Tanakitivirul M. Epidemiology of Behcet's Disease in Thai patients. J Med Assoc Thai. 2006;89:S182-86.

60. Pathanapitoon K, Kunavisarut P, Saravuttikul FA, Rothova A ocular manifestations and visual outcomes of Behcet's uveitis in a Thai population. Ocul Immunol Inflamm 2017: 1-5. https://doi. org/10.1080/09273948.2017.1351570. [Epub ahead of print]

61. Chung YM, Lin YC, Tsai CC, Huang DF. Behcet's disease with uveitis in Taiwan. J Chin Med Assoc. 2008;71:509-16.

62. Lee YB, Lee SY, Choi JY, Lee JH, Chae HS, Kim JW, et al. Incidence, prevalence, and mortality of Adamantiades-Behcet's disease in Korea: a nationwide, population-based study (2006-15). J Eur Acad Dermatol Venereol. 2018;32:999-1003.

63. Kim JN, Kwak SG, Choe JY, Kim SK. The prevalence of Behcet's disease in Korea: data from health insurance review and assessment service from 2011 to 2015. Clin Exp Rheumatol. 2017;35(Suppl 108):38-42.

64. Yazici H, Seyahi E, Hatemi G, Yazici Y. Behcet syndrome: a contemporary view. Nat Rev Rheumatol. 2018;14:107-19.

65. Cho SB, Cho S, Bang D. New insights in the clinical understanding of Behcet's disease. Yonsei Med J. 2012;53:35-42.

66. Chung YR, Lee ES, Kim MH, Lew HM, Song JH. Changes in ocular manifestations of Behcet disease in korean patients over time: A single-center experience in the 1990s and 2000s. Ocul Immunol Inflamm. 2015;23:157-61.

67. Kirino Y, Ideguchi H, Takeno M, Suda A, Higashitani K, Kunishita Y, et al. Continuous evolution of clinical phenotype in 578 japanese patients with Behcet's disease: a retrospective observational study. Arthritis Res Ther. 2016;18:217.

68. International Team for the Revision of the International Criteria for Behcet's D. The international criteria for Behcet's dsease (ICBD): a collaborative study of 27 countries on the sensitivity and specificity of the new criteria. J Eur Acad Dermatol Venereol. 2014;28:338-47.

69. Kaburaki T, Namba K, Sonoda KH, Kezuka T, Keino H, Fukuhara T, et al. Behcet's disease ocular attack score 24: evaluation of ocular disease activity before and after initiation of infliximab. Jpn J Ophthalmol. 2014;58:120-30.

70. Namba K, Goto H, Kaburaki T, Kitaichi N, Mizuki N, Asukata $\mathrm{Y}$, et al. A major review: current aspects of ocular Behcet's disease in Japan. Ocul Immunol Inflamm. 2015;23(Suppl 1): S1-23.

71. Ohara K. [Clinical manifestations of ocular sarcoidosis in japanese patients]. Nihon Rinsho. 1994;52:1577-81.

72. Choi SY, Lee JH, Won JY, Shin JA, Park YH. Ocular manifestations of biopsy-proven pulmonary sarcoidosis in Korea. J Ophthalmol. 2018;2018:9308414. 
73. Matsuo T, Fujiwara N, Nakata Y. First presenting signs or symptoms of sarcoidosis in a japanese population. Jpn J Ophthalmol. 2005;49:149-52.

74. Birnbaum AD, French DD, Mirsaeidi M, Wehrli S. Sarcoidosis in the national veteran population: association of ocular inflammation and mortality. Ophthalmology. 2015;122:934-8.

75. Asukata Y, Ota M, Meguro A, Katsuyama Y, Ishihara M, Namba $\mathrm{K}$, et al. Lack of association between toll-like receptor 4 gene polymorphisms and sarcoidosis-related uveitis in Japan. Mol Vis. 2009;15:2673-82.

76. Herbort CP, Rao NA, Mochizuki M. Members of scientific committee of first international workshop on ocular s. International criteria for the diagnosis of ocular sarcoidosis: results of the first international workshop on ocular sarcoidosis (IWOS). Ocul Immunol Inflamm. 2009;17:160-9.

77. Takase H, Shimizu K, Yamada Y, Hanada A, Takahashi H, Mochizuki M. Validation of international criteria for the diagnosis of ocular sarcoidosis proposed by the first international workshop on ocular sarcoidosis. Jpn J Ophthalmol. 2010;54:529-36.

78. Acharya NR, Browne EN, Rao N, Mochizuki M. International ocular sarcoidosis working g. Distinguishing features of ocular sarcoidosis in an international cohort of uveitis patients. Ophthalmology. 2018;125:119-26.

79. Abe C, Iwai K, Mikami R, Hosoda Y. Frequent isolation of propionibacterium acnes from sarcoidosis lymph nodes. Zent Bakteriol Mikrobiol Hyg A. 1984;256:541-7.

80. Yamada T, Eishi Y, Ikeda S, Ishige I, Suzuki T, Takemura T, et al. In situ localization of propionibacterium acnes DNA in lymph nodes from sarcoidosis patients by signal amplification with catalysed reporter deposition. J Pathol. 2002;198:541-7.

81. Nagata K, Eishi Y, Uchida K, Yoneda K, Hatanaka H, Yasuhara $\mathrm{T}$, et al. Immunohistochemical detection of propionibacterium acnes in the retinal granulomas in patients with ocular sarcoidosis. Sci Rep. 2017;7:15226.

82. Werner JL, Escolero SG, Hewlett JT, Mak TN, Williams BP, Eishi $\mathrm{Y}$, et al. Induction of pulmonary granuloma formation by propionibacterium acnes is regulated by myd88 and nox 2 . Am $\mathrm{J}$ Respir Cell Mol Biol. 2017;56:121-30.

83. Chen ES, Moller DR. Etiologies of sarcoidosis. Clin Rev Allergy Immunol. 2015;49:6-18.

84. Matsou A, Tsaousis KT. Management of chronic ocular sarcoidosis: challenges and solutions. Clin Ophthalmol. 2018;12:519-32.

85. Chee SP, Jap A, Bacsal K. Spectrum of Vogt-Koyanagi-Harada disease in Singapore. Int Ophthalmol. 2007;27:137-42.

86. Yang P, Ren Y, Li B, Fang W, Meng Q, Kijlstra A. Clinical characteristics of Vogt-Koyanagi-Harada syndrome in chinese patients. Ophthalmology. 2007;114:606-14.

87. Fong $\mathrm{AH}, \mathrm{Li} \mathrm{KK}$, Wong D. Choroidal evaluation using enhanced depth imaging spectral-domain optical coherence tomography in Vogt-Koyanagi-Harada disease. Retina. 2011;31:502-9.

88. Nakayama M, Keino H, Okada AA, Watanabe T, Taki W, Inoue M, et al. Enhanced depth imaging optical coherence tomography of the choroid in Vogt-Koyanagi-Harada disease. Retina. 2012;32:2061-9.

89. Tagawa Y, Namba K, Mizuuchi K, Takemoto Y, Iwata D, Uno $\mathrm{T}$, et al. Choroidal thickening prior to anterior recurrence in patients with Vogt-Koyanagi-Harada disease. Br J Ophthalmol. 2016;100:473-7.

90. Egawa M, Mitamura Y, Akaiwa K, Semba K, Kinoshita T, Uchino E, et al. Changes of choroidal structure after corticosteroid treatment in eyes with Vogt-Koyanagi-Harada disease. $\mathrm{Br}$ J Ophthalmol. 2016;100:1646-50.

91. Miura M, Makita S, Yasuno Y, Tsukahara R, Usui Y, Rao NA, et al. Polarization-Sensitive Optical Coherence Tomographic Documentation of Choroidal Melanin Loss in Chronic VogtKoyanagi-Harada Disease. Invest Ophthalmol Vis Sci. 2017;58:4467-76.

92. Errera MH, Fardeau C, Cohen D, Navarro A, Gaudric A, Bodaghi B, et al. Effect of the duration of immunomodulatory therapy on the clinical features of recurrent episodes in Vogt-Koyanagi-Harada disease. Acta Ophthalmol. 2011;89: e357-366.

93. Lai TY, Chan RP, Chan CK, Lam DS. Effects of the duration of initial oral corticosteroid treatment on the recurrence of inflammation in Vogt-Koyanagi-Harada disease. Eye (Lond). 2009;23:543-8.

94. Park UC, Cho IH, Lee EK, Yu HG. The effect on choroidal changes of the route of systemic corticosteroids in acute VogtKoyanagi-Harada disease. Graefes Arch Clin Exp Ophthalmol. 2017;255:1203-11.

95. Andreoli CM, Foster CS. Vogt-Koyanagi-Harada disease. Int Ophthalmol Clin. 2006;46:111-22.

96. Umran RMR, Shukur ZYH. Rituximab for sight-threatening refractory pediatric Vogt-Koyanagi-Harada disease. Mod Rheumatol. 2018;28:197-9.

97. Niccoli L, Nannini C, Cassara E, Gini G, Lenzetti I, Cantini F. Efficacy of infliximab therapy in two patients with refractory Vogt-Koyanagi-Harada disease. $\mathrm{Br} \quad \mathrm{J}$ Ophthalmol. 2009;93:1553-4.

98. Tseng ST, Yao TC, Huang JL, Yeh KW, Hwang YS. Clinical manifestations in uveitis patients with and without rheumatic disease in a chinese population in Taiwan. J Microbiol Immunol Infect. 2017;50:798-804.

99. Oruc S, Kaplan AD, Galen M, Kaplan HJ. Uveitis referral pattern in a midwest university eye center. Ocul Immunol Inflamm. 2003;11:287-98.

100. Jones NP. The manchester uveitis clinic: the first 3000 patients-epidemiology and casemix. Ocul Immunol Inflamm. 2015;23:118-126.0. 